\title{
Early and late do-not-resuscitate (DNR) decisions in patients with terminal COPD: a retrospective study in the last year of life
}

This article was published in the following Dove Press journal: International Journal of COPD

\author{
Pin-Kuei Fu ${ }^{1-4}$ \\ Yu-Chi Tung' \\ Chen-Yu Wang ${ }^{2}$ \\ Sheau-Feng Hwang ${ }^{5,6}$ \\ Shin-Pin $\operatorname{Lin}^{7}$ \\ Chiann-Yi Hsu ${ }^{8}$ \\ Duan-Rung Chen' \\ 'Institute of Health Policy and \\ Management, National Taiwan \\ University, Taipei, Taiwan; ${ }^{2}$ Department \\ of Critical Care Medicine, Taichung \\ Veterans General Hospital, \\ Taichung, Taiwan; ${ }^{3}$ Department of \\ Biotechnology, Hungkuang University, \\ Taichung, Taiwan; ${ }^{4}$ School of Chinese \\ Medicine, China Medical University, \\ Taichung, Taiwan; ${ }^{5}$ Department of \\ Obstetrics and Gynecology, Taichung \\ Veterans General Hospital, Taichung, \\ Taiwan; ${ }^{6}$ Palliative Care Unit, \\ Taichung Veterans General Hospital, \\ Taichung, Taiwan; ${ }^{7}$ Computer and \\ Communications Center, Taichung \\ Veterans General Hospital, Taichung, \\ Taiwan; ${ }^{8}$ Biostatistics Task Force, \\ Taichung Veterans General Hospital, \\ Taichung, Taiwan; ${ }^{9}$ Institute of \\ Health Behaviors and Community \\ Sciences, National Taiwan University, \\ Taipei, Taiwan
}

Correspondence: Duan-Rung Chen Institute of Health Behaviors and Community Sciences, National Taiwan University, No 17, Xu-Zhou Road, Taipei I0055, Taiwan $\mathrm{Tel}+886233668066$ Fax +886 22 39| I308 Email duan@ntu.edu.tw
Purpose: The unpredictable trajectory of COPD can present challenges for patients when faced with a decision regarding a do-not-resuscitate (DNR) directive. The current retrospective analysis was conducted to investigate factors associated with an early DNR decision (prior to last hospital admission) and differences in care patterns between patients who made DNR directives early vs late.

Patients and methods: Electronic health records (EHR) were reviewed from 271 patients with terminal COPD who died in a teaching hospital in Taiwan. Clinical parameters, patterns of DNR decisions, and medical utilization were obtained. Those patients who had a DNR directive earlier than their last (terminal) admission were defined as "Early DNR" (EDNR).

Results: A total of 234 (86.3\%) patients died with a DNR directive, however only $30 \%$ were EDNR. EDNR was associated with increased age (OR=1.07; 95\% CI: 1.02-1.12), increased ER visits $(\mathrm{OR}=1.22 ; 95 \% \mathrm{CI}: 1.10-1.37)$, rapid decline in lung function $(\mathrm{OR}=3.42 ; 95 \% \mathrm{CI}$ : $1.12-10.48)$, resting heart rate $\geq 100(\mathrm{OR}=3.02 ; 95 \% \mathrm{CI}: 1.07-8.51)$, and right-sided heart failure $(\mathrm{OR}=2.38 ; 95 \% \mathrm{CI}: 1.10-5.19)$. The median time period from a DNR directive to death was 68.5 days in EDNR patients and 5 days in "Late DNR" (LDNR) patients, respectively $(P<0.001)$. EDNR patients died less frequently in the intensive care unit $(P<0.001)$, received less frequent mechanical ventilation (MV; $P<0.001)$, more frequent non-invasive MV $(P=0.006)$, and had a shorter length of hospital stay $(P=0.001)$.

Conclusions: Most patients with terminal COPD had DNR directives, however only $30 \%$ of DNR decisions were made prior to their last (terminal) hospital admission. Further research using these predictive factors obtained from EHR systems is warranted in order to better understand the relationship between the timing associated with DNR directive decision making in patients with terminal COPD.

Keywords: do-not-resuscitate, electronic health record, medical utilization, share decision making

\section{Introduction}

COPD is a chronic illness that presents as a chronic productive cough and progressive shortness of breath. ${ }^{1}$ COPD was the seventh leading cause of death in Taiwan in 2015 and estimates suggest it will be the third leading cause of death worldwide in 2030. ${ }^{2,3}$ Patients with advanced COPD often have a poor prognosis ${ }^{4}$; however, advanced COPD patients receive intensive care more frequently compared with patients diagnosed with lung cancer. ${ }^{5-9}$ Patients with advanced COPD have increased comorbidities, spend more days in the hospital, have more invasive 
procedures, are more likely to die in the intensive care unit (ICU) and are less likely to have a do-not-resuscitate (DNR) directive. ${ }^{10-13}$

Cardiopulmonary resuscitation (CPR) performed in patients with a terminal illness is often ineffective and is associated with a reduction in quality of end-of-life care. ${ }^{14}$ A DNR directive indicates a patient's refusal to accept CPR when suffering from cardiac or respiratory arrest and is one of the most commonly discussed advance directives in palliative care. ${ }^{15,16}$

In 2000, the Hospice Palliative Care Act (HPCA) became a law in Taiwan, with amendments following in 2002, 2012, and 2013. ${ }^{17,18}$ People who suffer from a terminal illness, when certified by two physicians, have the right to refuse CPR. ${ }^{18}$ According to the HPCA, a DNR directive can be made in one of two ways: signed by a competent terminally ill patient (DNR will) or by a close relative (DNR consent) when the patient is no longer capable of making that decision for himself/herself. ${ }^{19}$

Other international guidelines have emphasized the importance of advance care directives being made early in patients with late stage $\mathrm{COPD}^{1,20}$; however, several barriers have been identified. COPD has an unpredictable disease trajectory. ${ }^{21,22}$ It is difficult to predict the death of a patient with COPD within six months..$^{23,24}$ Common parameters for prognostic criteria include measures of lung function, degree of hypoxia, history of hospitalization, and recent ventilator support - all of which have been found to be unreliable. ${ }^{25-28}$ Therefore, the timing of decisions regarding DNR directives in most patients with COPD may occur closer to death than not, and that decision may not be made by the patient themselves.

The aim of this study was to investigate factors associated with an early DNR decision (prior to last [terminal] hospital admission) and differences in care patterns between patients who made DNR directives early vs late. The timing of DNR decisions, who made the DNR decision, and the medical utilization of patients with COPD who died in a medical center in Taiwan were analyzed. Factors associated with early DNR decisions as obtained from hospital electronic health records (EHR) were also analyzed to provide additional insight for physicians, patients and their families to support their decision making when faced with a decision regarding a DNR directive.

\section{Methods}

Consecutive patients whose primary or secondary cause of death was COPD (based on ICD, ninth revision, Clinical
Modification [ICD-9-CM] coding) between 2011 and 2015, and whose death occurred in Taichung Veterans General Hospital (TCVGH), Taiwan, were included in this retrospective observational cohort study. Subjects with fewer than two TCVGH visits for the management of the symptoms associated with their COPD in the last year of life were excluded. TCVGH is a tertiary teaching hospital and the only public medical center located in central Taiwan. Patient demographics, diagnostic test results, treatment history, including palliative care, at TCVGH, was collected using the EHR system. The study protocol was fully reviewed and approved by the Institutional Review Board of the Taichung Veterans General Hospital (TCVGH-IRB) Taiwan (IRB number: CE17017A, date of approval: 11/22/2016). The requirement for informed patient consent was waived by the TCVGH internal review board considering the retrospective study design and the availability of all data via electronic medical records. Only de-identified patient data was used in this study.

\section{Study population}

EHRs from a total of 271 patients were included in the analysis. Eligible patients were $\geq 40$ years of age, had been diagnosed with COPD (ICD-9-CM codes 491.x, 492.x, and 496.x), had been admitted to the hospital for acute care, and died in the hospital between June 1, 2011 and December 31, 2015. Patients who met the inclusion criteria but were discharged in critical condition or terminal status were also included in the analysis.

\section{Operational definitions of outcome measures}

All subjects were validated according to the official criteria for "terminal status in COPD." ${ }^{29}$ Terminal status in COPD refers to having symptoms of dyspnea at rest, a progressive condition, and any of the following conditions: 1) Respiratory insufficiency (with or without oxygen support $\left[\mathrm{PaO}_{2} \leq 55 \mathrm{mmHg}\right.$, $\mathrm{PaCO}_{2} \geq 50 \mathrm{mmHg}$, or $\mathrm{O}_{2}$ saturation $\left.\leq 88 \%\right]$ ); 2) $\mathrm{FEV}_{1} \leq 30 \%$ of predicted; 3) $\mathrm{FEV}_{1}$ declined $\geq 40 \mathrm{~mL} /$ year; 4) Weight loss $\geq 10 \%$ in 6 months; 5) Resting heart rate $\geq 100 / \mathrm{min}$; 6) Right-sided heart failure; and 7) Multiple comorbidities: (eg, cachexia, recurrent infection, depression, or multiple comorbidities) ${ }^{8,9}$

Patients with COPD or their surrogates who had a DNR directive prior to their last (terminal) admission to the hospital were classified as Early DNR (EDNR). Whereas, Late DNR (LDNR) patients were those who implemented a DNR directive during their last admission. 


\section{Assessment}

We collected data on patient age, gender, pulmonary function test results $\left(\mathrm{FEV}_{1} / \mathrm{FVC}\right.$ ratio and $\mathrm{FEV}_{1} \%$ ), heart function (two-dimensional echocardiography), medical utilization (number of emergency room (ER) visits and hospitalizations), and any CPR (cardiac pulmonary resuscitation) within 1 year prior to death. Additional information obtained during the last (terminal) hospital admission included whether admitted from the ER, died on the service of a pulmonologist, died in the ICU, or experienced mechanical ventilation (such as invasive and non-invasive mechanical ventilation). The frequency of each criterion met by each patient with COPD was calculated. Furthermore, timing of a signed DNR directive and the patient status (terminal or not terminal) was also recorded. The total number of days from each patient's signed DNR consent until their deaths, as well as the number of days from physician confirmed terminal status to patient death were analyzed.

\section{Statistical analysis}

Statistical analyses were completed using SPSS version 22.0 (International Business Machines Corp, Armonk, NY, USA). For nonparametric distribution data, differences between groups were assessed using a Mann-Whitney U test and results were presented as median and interquartile range (IQR). The categorical variables were presented as frequency and percentage and analyzed using the chi-squared test. Factors associated with EDNR were assessed using univariate analysis and those with significant difference were assessed using multivariate analysis. The strength of association was presented as the odds ratio (OR) and $95 \%$ confidence intervals (CI). All results with $P<0.05$ were deemed to be statistically significant.

\section{Results}

\section{Characteristics of COPD deaths}

A total of 271 deaths due to COPD fit the enrollment criteria.

Patient characteristics and the study flow chart are summarized in Table 1 and Figure 1. Patients with COPD who died in the hospital were aged, predominately male, and experienced frequent ER visits and hospitalizations. Most patients (94.5\%) were admitted from the ER on their last (terminal) admission to the hospital, 59.8\% of patients died while being treated by a pulmonologist, and $32.5 \%$ died in the ICU. Despite $86.3 \%$ of patients having a DNR directive, $83.0 \%$ still experienced mechanical ventilation (MV) and $67.5 \%$ experienced invasive MV. Only $11.1 \%$ had been
Table I Demographic characteristics of patients with COPD who died in a medical center over a period of 5 years (20I I-20I5) $(\mathrm{N}=27 \mathrm{I})$

\begin{tabular}{|c|c|}
\hline Characteristics & Data \\
\hline Age (Median, IQR) & $83(77-88)$ \\
\hline Male & $249(91.9 \%)$ \\
\hline \multicolumn{2}{|l|}{$\begin{array}{l}\text { Pulmonary function test within I year prior } \\
\text { to death (Median, IQR) }(n=96)\end{array}$} \\
\hline $\mathrm{FEV}_{1} / \mathrm{FVC} \%$ & $48.5(39-62)$ \\
\hline $\mathrm{FEV}_{1} \%$ & $60.5(40-81.8)$ \\
\hline \multicolumn{2}{|l|}{$\begin{array}{l}\text { Medical utilization within I year prior to death } \\
\text { (Median, IQR) }\end{array}$} \\
\hline Number of ER visits & $2(I-3)$ \\
\hline Number of hospitalizations & I (I-3) \\
\hline Experienced CPR & $18(6.6 \%)$ \\
\hline \multicolumn{2}{|l|}{ Medical utilization in the last admission } \\
\hline Admitted from ER & $256(94.5 \%)$ \\
\hline Died on the service of a pulmonologist & $162(59.8 \%)$ \\
\hline Died in the ICU & $88(32.5 \%)$ \\
\hline Experienced mechanical ventilation & $225(83.0 \%)$ \\
\hline Had only Invasive MV & $119(43.9 \%)$ \\
\hline Had only NIPPV & $106(39.1 \%)$ \\
\hline Ever had both MV and NIPPV & $64(23.6 \%)$ \\
\hline Extubated with NIPPV support & $136(50.2 \%)$ \\
\hline Clinical indicators for palliative care (Median, IQR) & $4(3-5)$ \\
\hline Patient wishes recorded (DNR) & $234(86.3 \%)$ \\
\hline DNR in the last admission prior to death & $164(70.1 \%)$ \\
\hline DNR within 30 days prior to death & $175(74.8 \%)$ \\
\hline $\begin{array}{l}\text { Time period from DNR request to death } \\
\text { (Median, IQR) }\end{array}$ & $8.5(3-32)$ \\
\hline Terminal status certified by a physician & $30(11.1 \%)$ \\
\hline Terminal status certificated in the last admission $(n=30)$ & $24(80.0 \%)$ \\
\hline
\end{tabular}

Abbreviations: DNR, do-not-resuscitate; ER, emergency room; FEV , forced expiration volume in the first second of expiration; FVC, forced vital capacity; ICU, intensive care unit; IQR, interquartile range; MV, mechanical ventilator; NIPPV, non-invasive positive pressure ventilator.

documented as being terminal by the attending physician, and almost $80 \%$ of these were documented during the last admission when the patient was near death. Although 86.3\% of patients had expressed an interest in establishing a DNR directive by themselves or via their family surrogates, greater than $70 \%$ of the DNR directives were made during the last admission prior to death.

\section{Validated official criteria for "terminal status in COPD"}

Since only $11.1 \%$ of COPD deaths were documented as terminal status near death, the terminal condition according to the official criteria required validation. ${ }^{29,30}$ In our retrospective analysis, all patients fit the official criteria for "terminal status in COPD." ${ }^{29}$ The top three criteria were respiratory insufficiency (94.1\%), multiple comorbidities (89.7\%), and resting heart rate greater than $100 \mathrm{bpm}(78.2 \%$; Table 2). 


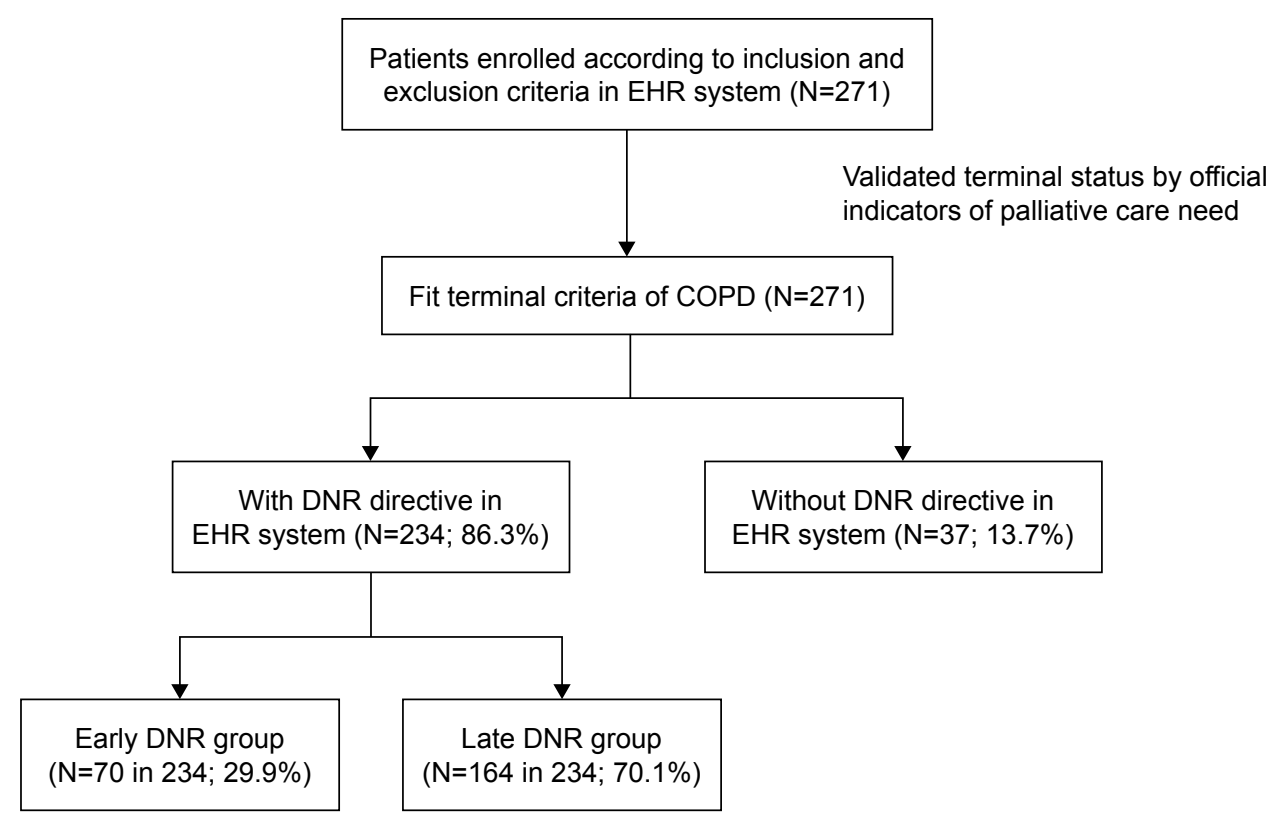

Figure I Study flow chart.

Notes: "Early DNR" was defined as "COPD patients or their surrogates who had DNR directive prior to their last admission." "Late DNR" was defined as "COPD patients or their surrogates who had DNR directive during their last admission."

Abbreviations: DNR, do-not-resuscitate; EHR, Electronic health records.

\section{"Early DNR," "Late DNR," and patterns of care during the last admission for COPD}

EDNR patients were aged, had more frequent ER visits and hospitalizations, and met the criteria for "terminal status" more frequently than LDNR patients (all $P<0.05$; Table 3 ). The EDNR group had an increased frequency of rapid declines in lung function $(P=0.014)$, resting heart rate $\geq 100 \mathrm{bpm}$ $(P=0.024)$ and right-sided heart failure $(P=0.003)$. EDNR patients died less frequently in the ICU $(P<0.001)$, used less invasive mechanical ventilation (MV) $(P<0.001)$, used non-invasive MV more frequently $(P=0.006)$ and had

Table 2 The official indicators of "terminal status in COPD" in Taiwan

\begin{tabular}{ll}
\hline Criteria & Fit cases (n, \%) \\
\hline $\begin{array}{l}\text { I) Respiratory insufficiency (even with oxygen } \\
\text { support, } \mathrm{PaO}_{2} \leq 55 \mathrm{mmHg}, \mathrm{PaCO}_{2} \geq 50 \mathrm{mmHg}\end{array}$ & $255(94.1 \%)$ \\
or $\mathrm{O}_{2}$ saturation $\left.\leq 88 \%\right)$ & \\
2) $\mathrm{FEV}_{1} \leq 30 \%$ of predicted & $44(16.2 \%)$ \\
3) $\mathrm{FEV}$, declined $\geq 40 \mathrm{~mL} /$ year & $72(26.6 \%)$ \\
4) Weight loss $\geq 10 \%$ in 6 months & $106(39.1 \%)$ \\
5) Resting heart rate $\geq 100 /$ min & $212(78.2 \%)$ \\
6) Right-sided heart failure & $116(42.8 \%)$ \\
7) Multiple comorbidities: (eg, cachexia, recurrent & $243(89.7 \%)$ \\
infection, depression, or multiple comorbidities) & \\
\hline
\end{tabular}

Note: "Terminal status in COPD": for COPD patients who suffered from breathlessness even when resting, and the condition continued to deteriorate (such as: repeated ER visits or hospitalizations due to pneumonia or respiratory failure), combined with any of the above conditions.

Abbreviation: $\mathrm{FEV}_{1}$, forced expiration volume in the first second of expiration. shorter lengths of stay before death $(P=0.001)$. The amount of time between DNR request to death was also significantly longer in the EDNR group compared with the LDNR group (median: 68.5 days and 5 days, respectively, $P<0.001$; Table 3 and Figure 2).

\section{Factors associated with EDNR}

Factors associated with EDNR are shown in Table 4. Using a univariate analysis, older age (odds ratio; $\mathrm{OR}=1.08 ; 95 \%$ CI: $1.04-1.13, P<0.001)$, frequent $\mathrm{ER}$ visits $(\mathrm{OR}=1.25 ; 95 \%$ CI: 1.13-1.38, $P<0.001)$, meeting more clinical indicators for palliative care (OR=1.32; 95\% CI: $1.09-1.60, P=0.005)$, rapid decline in pulmonary function $(\mathrm{OR}=2.23 ; 95 \% \mathrm{CI}$ : $1.22-4.10, P=0.009)$, resting heart rate $\geq 100 \mathrm{bpm}(\mathrm{OR}=2.56$; 95\% CI: 1.18-5.59, $P=0.018$ ), and right-sided heart failure (OR=2.49; 95\% CI: 1.40-4.42, $P=0.002)$ were associated with EDNR. "Terminal status documented by a physician" was not correlated with an early DNR directive $(\mathrm{OR}=1.97$; 95\% CI: 0.90-4.32, $P=0.09$ ). Multivariate analysis was applied to those factors found to be significant with univariate analysis. The multivariate analysis showed that older age (OR=1.07; 95\% CI: 1.02-1.12, $P=0.005)$, frequent $E R$ visits $(\mathrm{OR}=1.22 ; 95 \% \mathrm{CI}: 1.10-1.37, P<0.001)$, rapid decline in pulmonary function $(\mathrm{OR}=3.42$; $95 \% \mathrm{CI}: 1.12-10.48$, $P=0.031)$, resting heart rate $\geq 100 \mathrm{bpm}(\mathrm{OR}=3.02 ; 95 \%$ CI: 1.07-8.51, $P=0.036$ ), and right-sided heart failure $(\mathrm{OR}=2.38 ; 95 \% \mathrm{CI}: 1.10-5.19, P=0.028)$ were significantly 
Table 3 Comparison of care pattern and terminal criteria between "Early DNR" and "Late DNR"

\begin{tabular}{|c|c|c|c|}
\hline Characteristics & $\begin{array}{l}\text { Early DNR } \\
(\mathbf{N}=\mathbf{7 0})\end{array}$ & $\begin{array}{l}\text { Late DNR } \\
(\mathrm{N}=164)\end{array}$ & $P$-value \\
\hline Age (Median, IQR) & $87(83-90)$ & $82(75-85.75)$ & $<0.001 * *$ \\
\hline Male & $62(88.6 \%)$ & 154 (93.9\%) & 0.257 \\
\hline \multicolumn{4}{|c|}{ Lung function test within I year prior to death (Median, IQR) (n=24 vs 56 $)$} \\
\hline $\mathrm{FEV}, \%$ & $51.5(38.3-77.3)$ & $59(38.5-81.8)$ & 0.785 \\
\hline \multicolumn{4}{|l|}{ Medical utilization within I year prior to death (Median, IQR) } \\
\hline Number of ER visits & $3(2-6)$ & $I(I-3)$ & $<0.001 * *$ \\
\hline Number of hospitalizations & $2(I-4)$ & $I(I-2)$ & $<0.001 * *$ \\
\hline Experienced CPR & $2(2.9 \%)$ & $4(2.4 \%)$ & 1.000 \\
\hline Terminal status recorded by physicians & $13(18.6 \%)$ & $17(10.4 \%)$ & 0.132 \\
\hline Numbers of clinical indicators met for terminal status & $4(3-5)$ & $3(3-4.75)$ & $0.001 * *$ \\
\hline \multicolumn{4}{|l|}{ Items that meet the official indicator of terminal status: } \\
\hline $\begin{array}{l}\text { I) Respiratory insufficiency (even with oxygen support, } \\
\mathrm{PaO}_{2} \leq 55 \mathrm{mmHg}, \mathrm{PaCO}_{2} \geq 50 \mathrm{mmHg} \text { or } \mathrm{O}_{2} \text { saturation } \leq 88 \% \text { ) }\end{array}$ & $66(94.3 \%)$ & $156(95.1 \%)$ & 0.755 \\
\hline 2) $\mathrm{FEV}_{1} \leq 30 \%$ of predicted & $16(22.9 \%)$ & $24(14.6 \%)$ & 0.180 \\
\hline 3) $\mathrm{FEV}_{\text {, declined } \geq 40 \mathrm{~mL} / \text { year }}$ & $27(38.6 \%)$ & $36(22.0 \%)$ & $0.014^{*}$ \\
\hline 4) Weight loss $\geq 10 \%$ in 6 months & $26(37.1 \%)$ & $68(4 \mid .5 \%)$ & 0.637 \\
\hline 5) Resting heart beats $\geq 100 / \mathrm{min}$ & $61(87.1 \%)$ & $119(72.6 \%)$ & $0.024 *$ \\
\hline 6) Right side heart failure & $43(61.4 \%)$ & $64(39.0 \%)$ & $0.003 * *$ \\
\hline $\begin{array}{l}\text { 7) Multiple comorbidities: (eg, cachexia, recurrent infection, } \\
\text { depression or multiple comorbidities) }\end{array}$ & $65(92.9 \%)$ & $147(89.6 \%)$ & 0.597 \\
\hline Time periods from making DNR directives to death & $68.5(10.5-292.8)$ & $5(2-14.8)$ & $<0.001 * *$ \\
\hline \multicolumn{4}{|l|}{ Medical utilization in the last admission } \\
\hline Admitted from $E^{\mathrm{a}}$ & $68(97.1 \%)$ & $153(93.3 \%)$ & 0.354 \\
\hline Died on the service of a pulmonologist & $44(62.9 \%)$ & $97(59.1 \%)$ & 0.700 \\
\hline Died in the ICU & $5(7.1 \%)$ & $65(39.6 \%)$ & $<0.00$ I** \\
\hline Experienced mechanical ventilator & $48(68.6 \%)$ & 145 (88.4\%) & $0.001 * *$ \\
\hline Only using invasive MV & $8(11.4 \%)$ & $85(51.8 \%)$ & $<0.001 * *$ \\
\hline Only using NIPPV & $40(57.1 \%)$ & $60(36.6 \%)$ & $0.006 * *$ \\
\hline Extubated with NIPPV support & $39(55.7 \%)$ & $89(54.3 \%)$ & 0.952 \\
\hline Length of stay in the last admission & II $.5(4.0-21.0)$ & $19.0(10.0-34.8)$ & $<0.001 * *$ \\
\hline
\end{tabular}

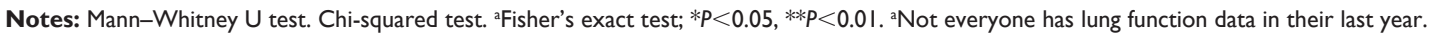

Abbreviations: CPR, cardio-pulmonary resuscitation; DNR, do not resuscitate; $E R$, emergency room; FEV , forced expiration volume in the first second of expiration; ICU, intensive care unit; IQR, interquartile range; MV, mechanical ventilator; NIPPV, Non-invasive positive pressure ventilator.

associated with early DNR requests. However, when using a multivariate analysis, age remained a significant factor and numbers of clinical indicators was not a significant factor (OR=0.68; 95\% CI: 0.44-1.06, $P=0.091)$.

\section{Discussion}

Three major findings were demonstrated in the current study. First, the official criteria for "terminal status in COPD" was validated - all enrolled COPD patients $(\mathrm{N}=271)$ fit the official

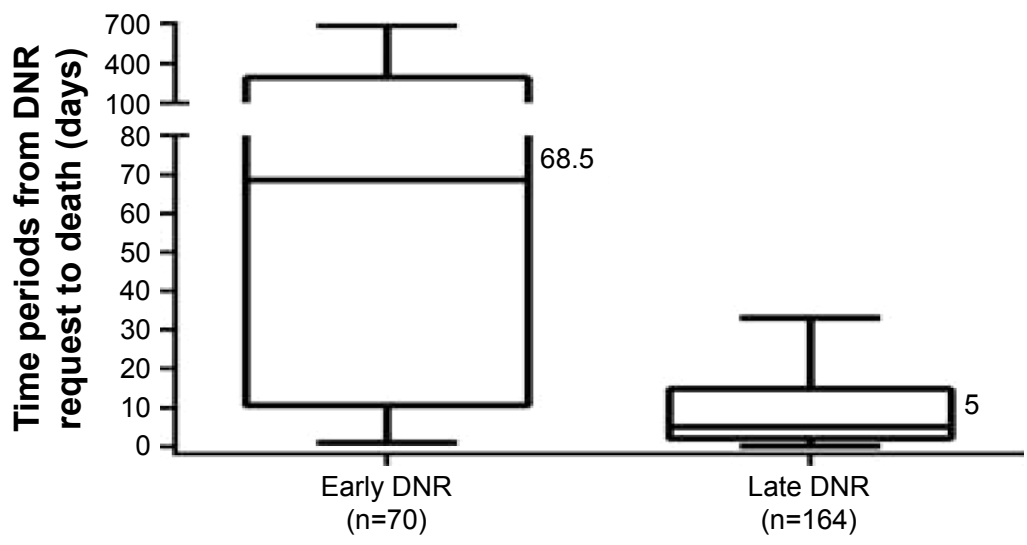

Figure 2 Period of time from DNR directive to death between "Early DNR" and "Late DNR" groups in terminal patients with COPD. Notes: Median: 68.5 days and 5 days, respectively, $P<0.001$.

Abbreviation: DNR, do not resuscitate. 
Table 4 Factors associated with EDNR

\begin{tabular}{|c|c|c|c|c|c|c|}
\hline \multirow[t]{2}{*}{ Characteristics } & \multicolumn{3}{|c|}{ Univariate analysis } & \multicolumn{3}{|c|}{ Multivariate analysis } \\
\hline & OR & $95 \% \mathrm{Cl}$ & $P$-value & OR & $95 \% \mathrm{Cl}$ & $P$-value \\
\hline Age & 1.08 & $(1.04-1.13)$ & $<0.001 * *$ & 1.07 & $(1.02-1.12)$ & $0.005^{* *}$ \\
\hline Male & 0.50 & $(0.19-1.33)$ & 0.168 & & & \\
\hline \multicolumn{7}{|l|}{ Lung function test within I year prior to death } \\
\hline $\mathrm{FEV}_{1} \%$ & 1.00 & $(0.98-1.01)$ & 0.688 & & & \\
\hline \multicolumn{7}{|l|}{ Medical utilization within I year prior to death } \\
\hline Number of ER visits & 1.25 & $(1.13-1.38)$ & $<0.00 I^{* *}$ & 1.22 & $(1.10-1.37)$ & $<0.001 * *$ \\
\hline Number of hospitalizations & 1.11 & $(0.98-1.26)$ & 0.093 & & & \\
\hline Number of clinical indicators met for terminal status & 1.32 & $(1.09-1.60)$ & $0.005^{* *}$ & 0.68 & $(0.44-1.06)$ & 0.091 \\
\hline Experienced CPR & 1.18 & $(0.21-6.58)$ & 0.853 & & & \\
\hline Terminal status certificated by physicians & 1.97 & $(0.90-4.32)$ & 0.090 & & & \\
\hline \multicolumn{7}{|l|}{ Terminal criteria } \\
\hline $\begin{array}{l}\text { I) Respiratory insufficiency (even with oxygen support, } \\
\mathrm{PaO}_{2} \leq 55 \mathrm{mmHg}, \mathrm{PaCO}_{2} \geq 50 \mathrm{mmHg} \text { or } \mathrm{O}_{2} \text { saturation } \leq 88 \% \text { ) }\end{array}$ & 0.85 & $(0.25-2.91)$ & 0.791 & & & \\
\hline 2) $\mathrm{FEV}_{1} \leq 30 \%$ of predicted & 1.73 & $(0.85-3.50)$ & 0.129 & & & \\
\hline 3) $\mathrm{FEV}$, declined $\geq 40 \mathrm{~mL} /$ year & 2.23 & $(1.22-4.10)$ & $0.009 * *$ & 3.42 & $(1.12-10.48)$ & $0.03 I^{*}$ \\
\hline 4) Weight loss $\geq 10 \%$ in 6 months & 0.83 & $(0.47-1.48)$ & 0.537 & & & \\
\hline 5) Resting heart beats $\geq 100 / \mathrm{min}$ & 2.56 & $(1.18-5.59)$ & $0.018^{*}$ & 3.02 & $(\mathrm{I} .07-8.5 \mathrm{I})$ & $0.036 *$ \\
\hline 6) Right side heart failure & 2.49 & $(1.40-4.42)$ & $0.002^{* *}$ & 2.38 & $(1.10-5.19)$ & $0.028 *$ \\
\hline $\begin{array}{l}\text { 7) Multiple comorbidities: (eg, cachexia, recurrent infection, } \\
\text { depression or multiple comorbidities) }\end{array}$ & 1.50 & $(0.53-4.25)$ & 0.442 & & & \\
\hline
\end{tabular}

Notes: Logistic regression. $* P<0.05$, $* * P<0.01$.

Abbreviations: CPR, cardio-pulmonary resuscitation; EDNR, early do-not-resuscitate; ER, emergency room; FEV , forced expiration volume in the first second of expiration.

criteria for terminal COPD. To the best of our knowledge, this is the first research to validate the official criteria for "terminal COPD" using real-world data from Taiwan.

Second, a gap of DNR decisions and the identification of terminal COPD status between patients/their surrogates and physicians was observed. In this cohort, 234 of the 271 patients with COPD (86.3\%) had signed a DNR directive before they died; however, only 30 of the 271 patients with COPD (11.1\%) had been confirmed and documented as being terminal status by physicians. Of the 234 cases with a DNR order, 233 cases were from family surrogates and only one patient made their own decision. According to the "Hospice Palliative Care Act" in Taiwan, two scenarios are possible when making a decision regarding a DNR directive. $\left.{ }^{17,18} 1\right) \mathrm{It}$ could be made by a patient themselves (DNR signed by patient), or 2) by their surrogate (DNR signed by surrogate). ${ }^{19}$ In this case it is possible the physicians had initiated conversations with family surrogates prior to last admission. Previous studies in Taiwan suggested patients who understand the prognosis of their disease or have previous discussions about a DNR order tend to have a DNR directive, however, in a real-world setting a family surrogate often needs to make a DNR directive on behalf of patients who cannot express their intention at end of life. ${ }^{16}$ In a local survey of 201 nursing home residents in Taiwan, the result showed that $16.4 \%$ had DNR directives, and $91 \%$ of these DNR directives were signed by family surrogates. ${ }^{31}$ This situation is the same as reports from Europe and North America that older patients prefer to make their final DNR directives by themselves. ${ }^{32,33}$ The current data not only reflect the unmet need for early advance care planning in COPD even when the "Hospice Palliative Care Act" is taken into account, but also show the uncertainty of physicians in identifying terminal status in patients with COPD. This phenomenon may contribute to the important barriers, such as poor communication between patients and physicians and the unpredictable trajectory of COPD when initiating DNR decisions. ${ }^{34-36}$ Third, we have identified factors associated with executing a DNR early by patients and/or their surrogates. EDNR patients had less intensive care, died less frequently in the ICU, and had shorter lengths of stay in the hospital in the last admission before they died when compared with the LDNR group. These results suggest that obtaining an early DNR directive (by patients or their surrogates) changed the attitude and treatment strategy of physicians. Only $11 \%$ of terminal patients with COPD were documented as in terminal status by physicians.

It is difficult to predict the death of patients with COPD within 6 months. ${ }^{22-24}$ Although pulmonary function tests (PFT) were important indicators of the prognosis for $\mathrm{COPD},{ }^{12,35}$ in the current study, only $35.4 \%$ (96 of 271 patients) had a PFT within 1 year prior to death. Heart failure is one of the most common comorbid conditions in COPD..$^{37,38}$ The presence of pulmonary hypertension and right-sided heart failure doubles the mortality in patients with COPD. ${ }^{39,40}$ In our data, severe COPD 
accompanied by documented right-sided heart failure was significantly associated with early DNR directives $(\mathrm{OR}=2.49$; 95\% CI: 1.40-4.42). We suggest that an annual follow-up PFT and heart function surveys are important in helping physicians to evaluate the disease progression of COPD.

There are some limitations to this study. First, the retrospective design collected data in a hospital. Therefore, it was possible to have missed patients due to inappropriate ICD-9-CM coding, underreporting, and/or incorrect electronic medical records diagnoses. Second, the care continuity of these COPD patients would be challenged for the missing data of medical utilizations. Since we have excluded subjects with fewer than two physician visits for COPD in TCVGH in their last year of life and the most critical COPD patients will be referred to TCVGH in central Taiwan, we could lower the impact of these two limitations. Third, we could not obtain the view point of patients and their surrogates due to the limitations of the study design. Fourth, the uncertainty of a clear definition of COPD terminal status would be a limitation for physicians expected to certify this status for their patients with COPD within an electronic medical record. Fifth, the results were based on a single medical center, so they may not represent the situation in other places or countries.

\section{Conclusion}

In this study, we currently report that despite $86.3 \%$ of patients with terminal COPD having DNR directives, only $11.1 \%$ had their terminal status documented by a physician, and $70 \%$ of DNR directives were made in the last admission before death. The major decision makers for the DNR directives were not the patients themselves, rather family surrogates. The time gap between "Early DNR" and "Late DNR" was nearly 60 days before death. By using information from EHRs, "Early DNR" was associated with older age, more ER visits, rapid decline in lung function, tachycardia and right-sided heart failure. Further research to routinely capture these predictive factors in existing EHR databases to help patients, their surrogates, and primary care physicians to share decision making in advanced COPD is warranted in the future.

\section{Acknowledgments}

The authors thank the Clinical Informatics Research \& Development Center and Taichung Veterans General Hospital.

\section{Author contributions}

The authors listed in the article meet conditions as following: Substantial contributions to conception and design, acquisition of data, or analysis and interpretation of data; drafting the article or revising it critically for important intellectual content; final approval of the version to be published; and agreement to be accountable for all aspects of the work in ensuring that questions related to the accuracy or integrity of any part of the work are appropriately investigated and resolved.

\section{Disclosure}

The authors report no conflicts of interest in this work.

\section{References}

1. Vogelmeier CF, Criner GJ, Martinez FJ, et al. Global strategy for the diagnosis, management, and prevention of chronic obstructive lung disease 2017 Report. GOLD Executive Summary. Am J Respir Crit Care Med. 2017;195(5):557-582.

2. 2015 statistical results on causes of death in Taiwan; 2017. Available from: http://www.mohw.gov.tw/mp-2.html. Accessed October 12, 2017.

3. Global surveillance, prevention and control of chronic respiratory diseases - A comprehensive approach. 2007. Available from: http://www. who.int/respiratory/publications/global_surveillance/en/. Accessed October 12, 2017.

4. Joshi M, Joshi A, Bartter T. Symptom burden in chronic obstructive pulmonary disease and cancer. Curr Opin Pulm Med. 2012;18(2): $97-103$.

5. Tsim S, Davidson S. End-of-life care in a general respiratory ward in the United Kingdom. Am J Hosp Palliat Care. 2014;31(2):172-174.

6. Curtis JR, Engelberg R, Young JP, et al. An approach to understanding the interaction of hope and desire for explicit prognostic information among individuals with severe chronic obstructive pulmonary disease or advanced cancer. J Palliat Med. 2008;11(4):610-620.

7. Au DH, Udris EM, Fihn SD, McDonell MB, Curtis JR. Differences in health care utilization at the end of life among patients with chronic obstructive pulmonary disease and patients with lung cancer. Arch Intern Med. 2006;166(3):326-331.

8. Curtis JR. Palliative and end-of-life care for patients with severe COPD. Eur Respir J. 2008;32(3):796-803.

9. Hyasat K, Sriram KB. Evaluation of the patterns of care provided to patients with COPD compared to patients with lung cancer who died in hospital. Am J Hosp Palliat Care. 2016;33(8):717-722.

10. Claessens MT, Lynn J, Zhong Z, et al. Dying with lung cancer or chronic obstructive pulmonary disease: insights from SUPPORT. Study to Understand Prognoses and Preferences for Outcomes and Risks of Treatments. J Am Geriatr Soc. 2000;48(5 Suppl):S146-S153.

11. Goodridge D, Lawson J, Duggleby W, Marciniuk D, Rennie D, Stang M. Health care utilization of patients with chronic obstructive pulmonary disease and lung cancer in the last 12 months of life. Resp Med. 2008; 102(6):885-891.

12. Chou WC, Lai YT, Huang YC, Chang CL, Wu WS, Hung YS. Comparing end-of-life care for hospitalized patients with chronic obstructive pulmonary disease and lung cancer in Taiwan. $J$ Palliat Care. 2013; 29(1):29-35.

13. Brown CE, Engelberg RA, Nielsen EL, Curtis JR. Palliative care for patients dying in the intensive care unit with chronic lung disease compared with metastatic cancer. Ann Am Thorac Soc. 2016;13(5): 684-689.

14. Zafar W, Ghafoor I, Jamshed A, Gul S, Hafeez H. Outcomes of inhospital cardiopulmonary resuscitation among patients with cancer. Am J Hosp Palliat Care. 2017;34(3):212-216.

15. Mentzelopoulos SD, Slowther AM, Fritz Z, et al. Ethical challenges in resuscitation. Intensive Care Med. 2018;44(6):703-716.

16. Fang YC, Pai MC, Wang LC, et al. Factors influencing family surrogates' intention with regard to do-not-resuscitate directive for patients with dementia. Clin Gerontol. 2018;10:1-9. 
17. Chang HT, Lin MH, Chen CK, Chou P, Chen TJ, Hwang SJ. Trends of do-not-resuscitate consent and hospice care utilization among noncancer descendents in a tertiary hospital in Taiwan between 2010 and 2014: a hospital-based observational study. Medicine. 2016;95(46):e5394.

18. Hospice Palliative Care Act; 2013. Available from: http://law.moj.gov. tw/Eng/LawClass/LawContent.aspx?PCODE=L0020066. Accessed May 29, 2018.

19. Liang YH, Wei CH, Hsu WH, et al. Do-not-resuscitate consent signed by patients indicates a more favorable quality of end-of-life care for patients with advanced cancer. Support Care Cancer. 2017;25(2):533-539.

20. Lanken PN, Terry PB, Delisser HM, et al. An official American Thoracic Society clinical policy statement: palliative care for patients with respiratory diseases and critical illnesses. Am J Respir Crit Care Med. 2008;177(8):912-927.

21. Steel A, Goldring J. End-of-life care in patients with chronic obstructive pulmonary disease. Br J Hosp Med. 2015;76(1):C10-C13.

22. Spathis A, Booth S. End of life care in chronic obstructive pulmonary disease: in search of a good death. Int J Chron Obstruct Pulmon Dis. 2008;3(1):11-29.

23. The SUPPORT Principal Investigators. A controlled trial to improve care for seriously ill hospitalized patients. The study to understand prognoses and preferences for outcomes and risks of treatments (SUPPORT). JAMA. 1995;274(20):1591-1598.

24. Coventry PA, Grande GE, Richards DA, Todd CJ. Prediction of appropriate timing of palliative care for older adults with non-malignant life-threatening disease: a systematic review. Age Ageing. 2005;34(3):218-227.

25. Hansen-Flaschen J. Chronic obstructive pulmonary disease: the last year of life. Resp Care. 2004;49(1):90-97.

26. Seneff MG, Wagner DP, Wagner RP, Zimmerman JE, Knaus WA. Hospital and 1-year survival of patients admitted to intensive care units with acute exacerbation of chronic obstructive pulmonary disease. JAMA. 1995;274(23):1852-1857.

27. Benzo R, Siemion W, Novotny P, et al. Factors to inform clinicians about the end of life in severe chronic obstructive pulmonary disease. J Pain Symptom Manage. 2013;46499(4):491-499.

28. McGhan R, Radcliff T, Fish R, Sutherland ER, Welsh C, Make B. Predictors of rehospitalization and death after a severe exacerbation of COPD. Chest. 2007;132(6):1748-1755.

29. Palliative care services open to terminally ill non-cancer patients in eight newly added categories. Officially Covered by National Health Insurance since September 1st, 2009; 2009. Available from: https:// www.nhi.gov.tw/english/News_Content.aspx?n=996D1B4B5DC483 43\&sms=F0EAFEB716DE7FFA\&s=37BA73280DCC9628. Accessed May 29, 2018.
30. Hsu NC, Lin YF, Shu CC, Yang MC, Wj K. Noncancer palliative care: the lost pieces in an acute care setting in Taiwan. Am J Hosp Pall Care. 2013;30(4):334-338

31. Lo YT, Wang JJ, Liu LF, Wang CN. Prevalence and related factors of do-not-resuscitate directives among nursing home residents in Taiwan. J Am Med Dir Assoc. 2010;11(6):436-442.

32. Agård A, Hermerén G, Herlitz J. Should cardiopulmonary resuscitation be performed on patients with heart failure? The role of the patient in the decision-making process. J Intern Med. 2000;248(4):279-286.

33. Frank C, Heyland DK, Chen B, Farquhar D, Myers K, Iwaasa K. Determining resuscitation preferences of elderly inpatients: a review of the literature. CMAJ. 2003;169(8):795-799.

34. Curtis JR, Engelberg RA, Nielsen EL, Au DH, Patrick DL. Patientphysician communication about end-of-life care for patients with severe COPD. Eur Respir J. 2004;24(2):200-205.

35. Janssen DJ, Curtis JR, Au DH, Dh A, et al. Patient-clinician communication about end-of-life care for Dutch and US patients with COPD. Eur Respir J. 2011;38(2):268-276.

36. Momen N, Hadfield P, Kuhn I, Smith E, Barclay S. Discussing an uncertain future: end-of-life care conversations in chronic obstructive pulmonary disease. A systematic literature review and narrative synthesis. Thorax. 2012;67(9):777-780.

37. Brown JP, Martinez CH. Chronic obstructive pulmonary disease comorbidities. Curr Opin Pulm Med. 2016;22(2):113-118.

38. Camiciottoli G, Bigazzi F, Magni C, et al. Prevalence of comorbidities according to predominant phenotype and severity of chronic obstructive pulmonary disease. Int J Chron Obstruct Pulmon Dis. 2016;11: 2229-2236.

39. Oswald-Mammosser M, Weitzenblum E, Quoix E, et al. Prognostic factors in COPD patients receiving long-term oxygen therapy. Importance of pulmonary artery pressure. Chest. 1995;107(5):1193-1198.

40. Shujaat A, Minkin R, Eden E. Pulmonary hypertension and chronic cor pulmonale in COPD. Int J Chron Obstruct Pulmon Dis. 2007;2(3): 273-282.
International Journal of COPD

\section{Publish your work in this journal}

The International Journal of COPD is an international, peer-reviewed journal of therapeutics and pharmacology focusing on concise rapid reporting of clinical studies and reviews in COPD. Special focus is given to the pathophysiological processes underlying the disease, intervention programs, patient focused education, and self management protocols.

\section{Dovepress}

This journal is indexed on PubMed Central, MedLine and CAS. The manuscript management system is completely online and includes a very quick and fair peer-review system, which is all easy to use. Visit http://www.dovepress.com/testimonials.php to read real quotes from published authors. 